\title{
Double stars: \\ a synergy between amateur and professional astronomers
}

\author{
Jean-Louis Agati, Daniel Bonneau, Sébastien Caille, Paul Couteau, \\ André Debackère, Jean Dommanget, Pierre Durand, René Gili, \\ Florent Losse, René Manté, Florence Mauroy, Guy Morlet, \\ Maurice Salaman, Edgar Soulié, Jean-Claude Thorel, Yvonne Thorel \\ and Pierre Verhas \\ Commission des Étoiles Doubles, Société Astronomique de France, \\ 3, Rue Beethoven, 75016 Paris, France \\ email: edgar.soulie@cea.fr
}

\begin{abstract}
In the field of visual double stars, a long term follow-up is required, since their orbital periods may reach several centuries. Created in 1981 within the Société Astronomique de France (SAF) with the support of the late Paul Muller (1910-2000), the Commission des Etoiles Doubles provides the framework for the necessary collaboration between professional and amateur astronomers, through generations. The late Dr. Paul Baize (1901-1995) was a model for its members. Several professional astronomers became scientific advisors of the Commission and have guided many works made by amateurs.
\end{abstract}

Keywords. Amateurs, binary stars

\section{Introduction}

The words "double star" introduced by the Greek astronomer Claudius Ptolemy in the 2nd century, refers to a set of two stars which, seen from the Earth, appear in very close directions. Double stars were scientific curiosities until William Herschel (17381822) published (Herschel 1803) his discovery of curved relatives trajectories for certain double stars, called physical pairs or binaries. The determination of the orbit of a binary would allow the determination of the sum of the masses of its components by means of a generalization of Johannes Kepler's third law when the parallax of the binary becomes known. The investigation of binaries became a full domain of astronomy.

Wilhelm Friedrich Struve (1793-1864) (Batten 1988), carried out with method and efficiency a working programme in four points, still topical:

(a) to discover and catalogue double stars

(b) to make micrometric measures of them

(c) to estimate their luminosities and colours

( $d$ ) to determine accurate positions by meridian observations.

In one of his books, the professional astronomer and discoverer of 2700 double stars Paul Couteau describes the passion of many talented observers of double stars in the 19th and 20th centuries (Couteau 1988). 


\section{French double stars enthousiasts and the SAF's Double Star Commission}

In France, Camille Flammarion (1842-1925), inspired populariser of astronomy and founder of the Société Astronomique de France (Fuentes and De La Cotardière 1994), was interested among other topics in double stars. Three French amateurs had a passion for double stars and made an important work. Robert Jonckheere (1888-1974) observed at his private observatory at Hem, at Strasbourg, at Greenwich when he took refuge in England, finally at Marseilles; he discovered more than three thousand double stars (Thorel 2009). Maurice Duruy (1894-1984) was the first to apply the diffraction grid micrometer invented by Ejnar Hertzsprung (1873-1967) to the measurement of double stars; he published his measures in the Journal des observateurs.

Pediatrician by profession, Paul Baize (1901-1995) devoted much effort to double stars, as an observer, an orbit calculator and a populariser in the magazine L'Astronomie for decades (Couteau 1988). A guide about double stars by Paul Couteau (Couteau 1978) incited the amateurs astronomers to measure them. An amateur astronomer, Pierre Durand created an informal group on double stars which was transformed into the Double Star Committee (Commission des étoiles Doubles) within the Société Astronomique de France in 1981, thanks to the support of the professional astronomer Paul Muller (19102000), inventor of a double image micrometer and discoverer of 700 double stars, who lavished his advice on amateurs for almost twenty years. In 1982, Pierre Durand organised at Marseilles a first summer meeting with the help of the late Émile Nègre and called professional astronomers who became scientific advisers to the Committee.

\section{Techniques for measuring visual double stars}

Amateurs of the Committee undertook the measurement of visual double stars, which is often difficult as a consequence of atmospheric turbulence.

\subsection{Measures with a filar micrometer}

Initiated in the years 1980s to the observation of visual double stars by Paul Couteau, the medicine professor Jacques Le Beau (1910-2000) made twelve series of measures with the $50 \mathrm{~cm}$ refractor of the Observatoire de la Côte d'Azur at Nice, two published in Astron. \& Astrophys., the ten other in Observations \& Travaux (O\&T). Pierre Durand and Jean-Claude Thorel made most of their measures with the $50 \mathrm{~cm}$ refractor of Nice. Jean-Claude Thorel published three series of measures in Astron. \& Astrophys., René Gili made his own with the 50 then the $74 \mathrm{~cm}$ refractors of Nice from 1987 to 1993; he published an article in Astronomische Nachrichten and another with Paul Couteau in Astron. \& Astrophys..

\subsection{The double image micrometer with a spar plate}

Invented by Bernard Lyot (1897-1952), used once by Henri Camichel (1907-2003) in 1949 for the measure of double stars, the double image micrometer with a spar plate was recommended by Paul Couteau for its accuracy. Upon the suggestion of Pierre Durand, this micrometer was developed in 1988 under the direction of Jean-Louis Agati with help from René-Georges Huret and Edgar Soulié. Upon the suggestion of Gino Farroni, the manufacturing of this micrometer was entrusted to the MECA-PRECIS company at Châtillon-sur-Indre (France). The users valued the precision of this micrometer, with which the magnitude difference between the components can be measured. 


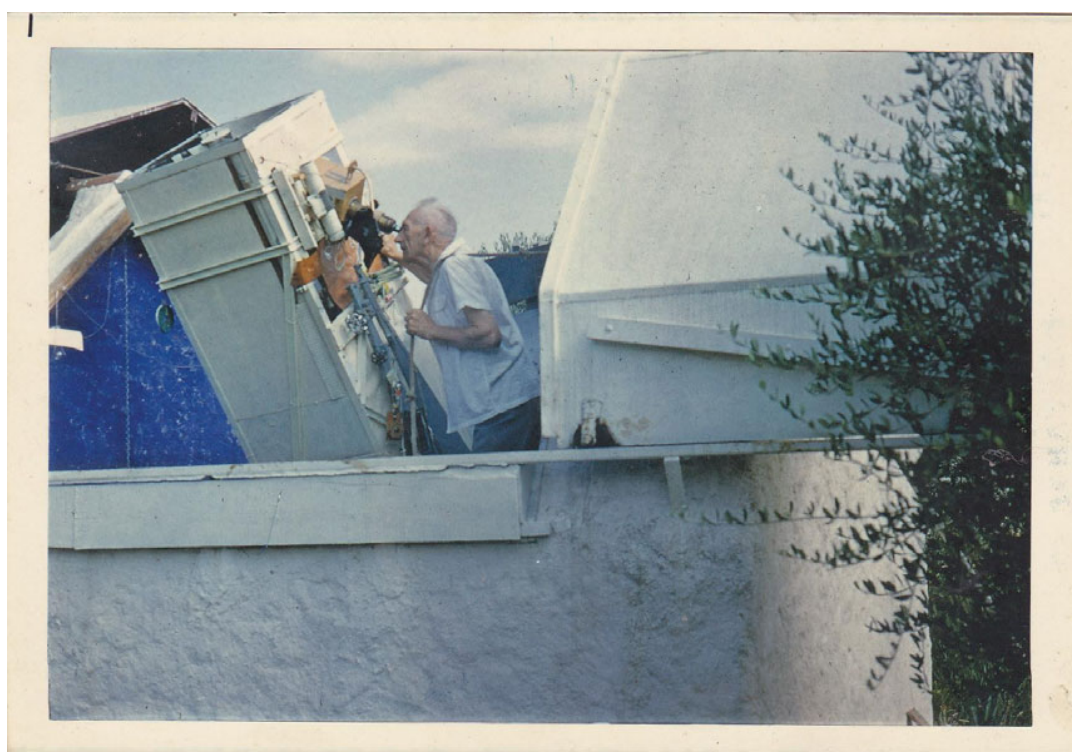

Figure 1. Maurice DURUY at the ocular of his $60 \mathrm{~cm}$ reflector at Le Rouret (Alpes-Maritimes).

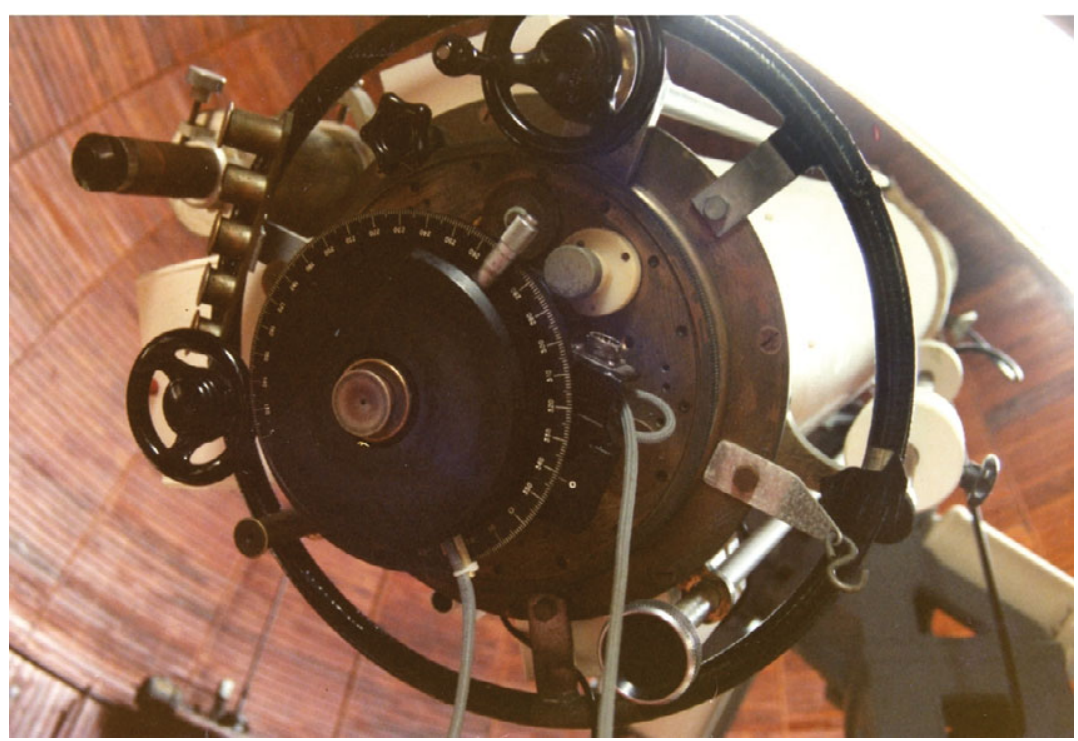

Figure 2. The filar micrometer installed at the $50 \mathrm{~cm}$ refractor at the Nice Observatory.

\subsection{The transit method}

Upon an initiative of André Debackere, Jacques Cazeneuve (1925-2007), Michel Lefebvre and the late Paul Viel tested the transit (or chronometer) method. The analysis of the dispersion of their measures led them to conclude that the precision of this method was insufficient.

\subsection{Photographic recording and measures of images of double stars}

The medicine professor Pierre Janny (1921-1993) resorted to photography of double stars and measured their position elements on his photographs with a densitometer. 


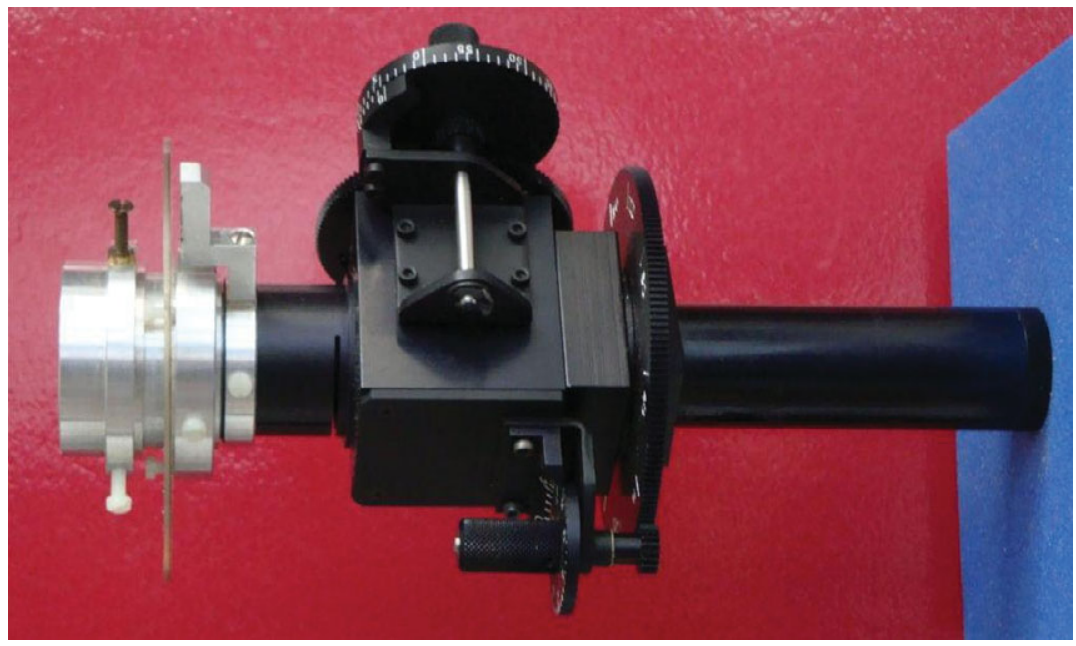

Figure 3. The double image micrometer with a spar plate invented by Bernard Lyot and developed by the Double Star Commission (SAF).

\subsection{The application of CCD cameras to double stars}

In the 1990s, cameras with charge coupled devices (CCD) became economically accessible to amateur astronomers. Gino Farroni suggested their use for the measurement of double stars to the Commission. The late Ghislain de Froment was interested. René Gili, Guy Morlet and Maurice salaman, together or separately, used a camera of brand LE2IM, model HiSis22, for the measurement of pairs with the 50 and $74 \mathrm{~cm}$ refractors of Nice, with exposure times about 0.1 second and an image acquisition frequency of $0.5 \mathrm{~Hz}$. The measures were published in Astron. \& Astrophys. (4 papers) and $O \& T$ ( 2 papers). From 2001 to 2005, the same and Pierre Durand, Florence et Pascal Mauroy (1956-2007) used the HiSis23 camera. In Saint-Pardon-de-Conques, Florent Losse uses an Audine camera. In the course of time, the magnitude and angular separation performances came closer to the limits set by the telescope diameter and the atmospheric turbulence.

\subsection{A new type of camera dubbed "EMCCD"}

In 2000, a new type of camera appeared on the market, combining the functions of charge transfer and electron multiplication. It allowed short exposure times of 20 or $10 \mathrm{~ms}$ with an acquisition frequency of $35 \mathrm{~Hz}$. For a few ms, the atmospheric turbulence being almost fixed, the images display a much better resolution than before. René Gili experimented two cameras of brand ANDOR, models LUCA and iXON, on the $74 \mathrm{~cm}$ refractor of Nice. Pairs having an angular separation equal to the diffraction limit of this refractor were separated.

\section{Softwares for binaries}

The acquired images are used to determine the position angle $\theta$ and the angular separation $\rho$ by means of a computer programme. Several programmes for the determination gave good results for wide pairs but not for close pairs. In particular, the software REDUC of Florent Losset, much used, combined the sorting of images, the measurement of selected images and the mean of the measures. For close pairs, the software SCAN developed

$\dagger$ http://www.astrosurf.com/hfosaf 


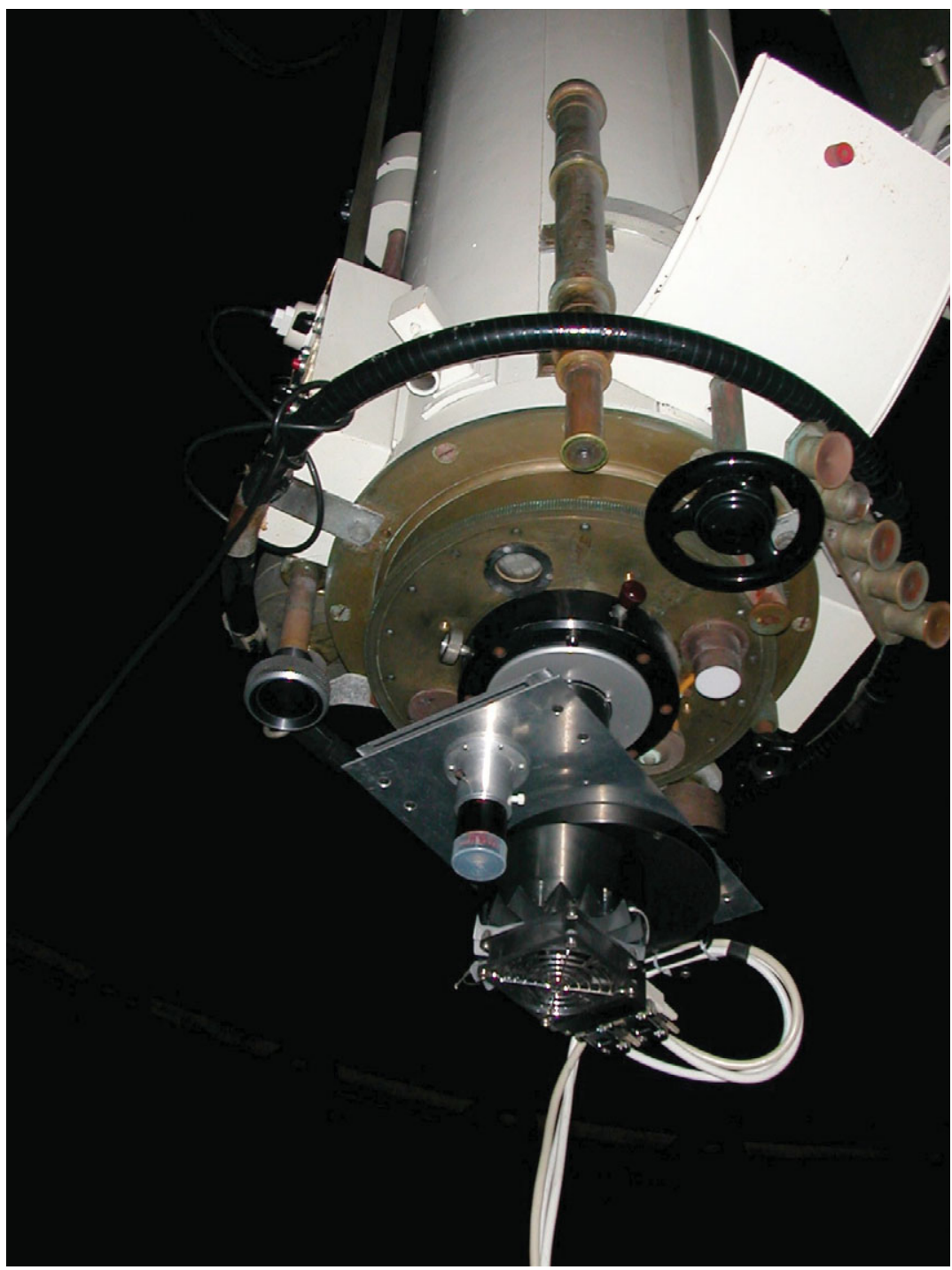

Figure 4. The CCD camera model HiSis23 of brand LE2IM at the focus of the $50 \mathrm{~cm}$ refractor of Nice Observatory.

by H. Jenkner and improved by D. Sinachopoulos compared the (monodimensional) profiles of observed and calculated illuminations in directions parallel to the image sides. To this comparison, Edgar Soulié, Guy Morlet and Maurice Salaman substituted that of the (bidimensional) observed and calculated illumination maps (Soulié \& Morlet 1997), using the empirical function $f(x)=\left[\exp \left(-a x^{2}\right)\right] /\left[1+b x^{2}\right]$ proposed by Pierre Bacchus (1923$2007)$ to depict the illumination decrease of a star image from its centre. Guy Morlet and Pierre Bacchus developed in the $\mathrm{C}$ programming language the software SURFACE (Morlet \& Salaman 2005) which combines the reading of the observed image file, the fitting of parameters and the display of observed and calculated images. Finally, the programme SURFACE was incorporated into the programme REDUC. 


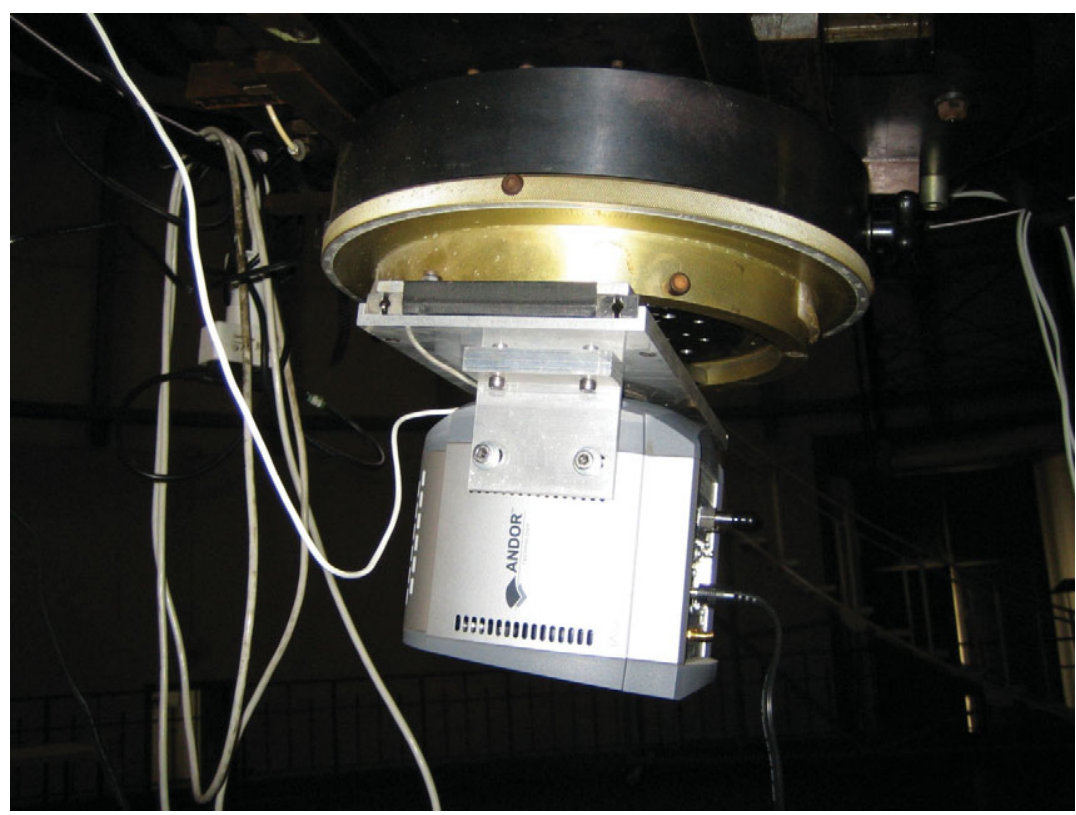

Figure 5. The EM-CCD camera model iXON of brand ANDOR attached to the $74 \mathrm{~cm}$ refractor of Nice Observatory.

\section{Checking positions}

In the 1980s, within the European working group in charge of the Input catalogue for the astrometric satellite Hipparcos, Jean Dommanget was responsible for double and multiple stars. They asked the amateurs of the Double Star Committee to check the positions of certain double or multiple stars selected for the Input catalogue. A few amateurs undertook these checks. For each object, the observer carefully noted what he saw in a field centred on the published position; if the pair (or multiple star) was not at the expected position, the observer searched for it in the vicinity. After the launch of the Hipparcos satellite, the checking work continued. In the course of his checking work on the sky, Jean-Claude Thorel discovered four pairs.

\section{Orbital determination}

Paul Baize published about hundred and fifty orbits of binaries. In 1954, he published in the magazine L'Astronomie an article in which he explained how to determine an orbit by a graphical method. In 1983, Michel Walbaum (a chemical engineer and amateur astronomer, who died in 1983) and Jean-Louis Duvent (engineer, amateur astronomer) tackled the search of invisible companions of double stars by investigating the perturbations which these companions induce on their orbits. Their article (Walbaum \& Duvent 1983) contains a prediction which has since been realised : "We are close to discover giant planets similar to Jupiter". In 1986, Edgar Soulié published a new method for the improvement of the orbit of a visual double star (Soulié 1986). Using a modified version of the programme for first orbit calculation of Edgar Soulié, René Manté published a series of 49 determinations of preliminary orbits of close (the first 4 in O\&T and the 45 next in the Information Circulars of Commission No. 26 (Double Stars) of the IAU between 1998 and 2006 . 
Jean Dommanget presented the orbit determination method of Thiele-Van den Bos (Dommanget 2000).

\section{The orientation of the orbital planes}

In 1968, Jean Dommanget wondered if the orientations of orbital planes of physical pairs were regularly distributed. But the astrometric measurements do not enable to discriminate between the ascending and descending nodes. Thus, one of the seven parameters which define the orientation of the orbit of a binary star, the position angle of the ascending node, is generally affected by an indetermination of 180 degrees. In order to lift this indetermination, it is necessary that radial velocities ascribed to identified components of the binary be known at several epochs. Thus, Jean Dommanget proposed to amateurs a programme comprising the search and the treatment of measures of radial velocities pertaining to visual binaries for which orbits have been published.. This programme, to which Pierre Bacchus intensely participated, is led by Daniel Bonneau and profits by the active collaboration of Pierre Verhas and more recently of Jean Louis Agati.

\section{Internet site and discussion forum}

Created by Sébastien Caille, the internet site of the Committee was opened in January 2006 at the address http://saf .etoilesdoubles.free.fr. The aim of this site is to let people know the activities of the Committee and to raise up vocations in the community of amateur astronomers. The column Articles/documents provides in electronical format articles and documents related to double stars, notably a book by Paul Couteau (Couteau 1978) and a book chapter by Pierre Durand (Durand 1987). The column Outils allows one to load tools or to become connected to several useful tools for double stars observers. The column Observations depicts current observation projects and calls to observations.

The discussion forum on double stars created and moderated by Pascal Mauroy was replaced in 2008 by a new forum moderated by Sébastien Caille. It has drawn several new people to the Double Star Committee.

\section{References}

Batten, A.H. 1988, Resolute and undertaking characters : the lives of Wilhelm and Otto Struve (Dordrecht: Reidel)

Couteau, P. 1978, L'observation des étoiles doubles visuelles (Paris: Flammarion) $\dagger$

Couteau, P. 1988, Ces astronomes fous du ciel ou l'histoire de l'observation des étoiles doubles (Aix-en-Provence: Edisud)

Dommanget, J. 2000, Observations \& Travaux, 52, 19

Durand, P. 1987, in Astronomie. Le guide de l'observateur, P. Martinez (ed) (Toulouse: Société d'Astronomie Populaire)

Fuentes, P., and de La Cotardière, P. 1994, Camille Flammarion (Paris: Editions Flammarion) Herschel, W. 1803, Philosophical Magazine, 93, 339

Morlet, G. \& Salaman, M. 2005, Observations \& Travaux, 61, 34

Soulié, E. 1986, Astron. Es Astrophys., 164, 408

Soulié, E. \& Morlet, G. 1997, in Visual double stars : formation, dynamics and evolutionary tracks, J.A. Docobo et al. (eds) (Dordrecht: Kluwer), p. 107

Thorel, J.-C. 2009, Robert Jonckheere (Agnières: Edition Le Temps Présent)

Walbaum, M. \& Duvent, J.-L. 1983, L'Astronomie, 97, 277

$\dagger$ out of print but available at http://saf .etoilesdoubles.free.fr 